\title{
Outsourcing performance quality assessment using data envelopment analytics
}

1. Mehrdokht Pournader

Macquarie Graduate School of Management, Macquarie University, Macquarie Park, NSW

2109, Australia

Email: mehrdokht.pournader@students.mq.edu.au

2. Andrew Kach

The Swiss Federal Institute of Technology Zurich, 8092 Zurich, Switzerland

Email: akach@ethz.ch

3. Behnam Fahimnia

Institute of Transport and Logistics Studies, The University of Sydney, NSW 2000, Australia

Email: behnam.fahimnia@sydney.edu.au

4. Joseph Sarkis

Foisie School of Business, Worcester Polytechnic Institute, Worcester, MA 01609-2280, USA

Email: jsarkis@wpi.edu

\section{Abstract}

The growth of vendor procurement and supply chain management simultaneously emerged as organizational outsourcing practices increased. Outsourcing, as an important strategic organizational practice, needs to be carefully examined from an organizational performance perspective to ensure satisfactory quality of services and goods from supply chains. This article provides a model for performance assessment of an outsourcer's processes in a supply chain comprised of several internal and external entities. Internal entities are entities in a supply chain that the outsourcer can manage and control. External entities are entities whose processes are not within the management sphere and control of the outsourcer, yet affect an outsourcer's performance. A slacks-based measure is incorporated into a hybrid network data envelopment analysis model to evaluate the outsourcer performance incorporating both entity types. A case study of a service supply chain in the banking industry comprised of a commercial bank, its sub-processes, and an external investment bank is used as an illustrative application of the model. Insights are presented and future research directions are identified.

Keywords: Outsourcing; Performance Measurement; Quality; Data Envelopment Analysis; Slacks-Based Measure; Hybrid Network; Supply Chain Management. 


\section{Introduction}

Strategic focus, core competency development, technological advancements, and everincreasing competitiveness in markets have motivated more companies to opt for outsourcing solutions (Tate et al., 2009; Steven et al., 2014). Outsourcing can occur anywhere throughout the supply chain, including upstream, downstream, and organizational processes especially where the inflow or outflow of material, information, or finances cannot be effectively and efficiently developed (Holcomb \& Hitt, 2007; Wuyts et al., 2015).

Despite the underlying operational and financial benefits that may accrue from the flexibility to outsource, numerous issues do arise. For example, as the scale and distance of outsourcing increases so do the costs associated with control and coordination amongst supply chain members (Hallikas et al., 2004; Ellram et al., 2007; Handley \& Benton Jr, 2013). Other related issues may include opportunistic behavior of suppliers and inadequate relationship management between outsourcer and supplier (Kenneth H Wathne \& Heide, 2000), poor quality of services/goods provided by suppliers (Franca et al., 2010), poor inventory management (Lee, 1997), and operational and logistics disruptions in supply chain tiers (Wagner \& Bode, 2008). Hence, increasing awareness and information about the quality and performance issues helps the outsourcer to better identify inefficiencies within its internal and external supply chain processes. There is a need for more investigations to extend the scope of quality assessment in outsourcing to consider supply chain operations as a whole (Handley \& Gray, 2013; Steven et al., 2014).

From an organizational performance perspective, outsourcing can result in information loss, information asymmetry, and lack of knowledge of the outsourced processes (Ellram et al., 2008; Handley \& Gray, 2013), which in turn inhibits the outsourcer from gaining proper insight into the quality issues that might arise from both outsourced and insourced supply chain 
processes. Usually the analytical models for performance assessment in supply chains consider a centralized supply chain system in which all the information is available to the outsourcer (Chang et al., 2014). In this article data envelopment analysis (DEA) is adopted to facilitate a comparative quality assessment in outsourcing activities built upon organizational performance and practiced in supply chains while considering the control and visibility limitations of outsourcing. DEA is a multiple-input multiple-output performance evaluation tool that has been extensively applied to supply chain management and evaluation problems (Liang et al., 2006; Xu et al., 2009). One particular form of DEA, network DEA, is a valuable tool for evaluating multi-tier supply chains (C. Chen \& Yan, 2011). Using a hybrid network DEA model developed by Chang et al. (2014) and a slacks-based measure (SBM) approach (Tone \& Tsutsui, 2009; Kao, 2014a), this study introduces a performance assessment methodology evaluating outsourced processes in both internal and external supply chain entities.

The contributions of this study are three fold. (1) This article accounts for relevant information from internal and external entities in a supply chain to accurately assess the performance of an outsourcer. (2) The combined SBM approach and hybrid network DEA model proposed for the first time in this study provides a customized performance assessment tool with a high discrimination power that could facilitate identifying sources of inefficiencies in supply chain processes. (3) This study is among the few conducted that encourage the application of network DEA instead of traditional DEA models due to their accuracy and extended applications in supply chain performance measurement.

The article is organized as follows. In Section 2, we review the literature of outsourcing and quality in supply chains. We also review the applications of DEA, specifically network DEA and the SBM approach, and their applicability to the context of our research. Section 3 includes developing the analytical model to compare performance in multiple supply chains 
that practice outsourcing. We test our proposed model in a service supply chain of Iranian commercial banks in Section 4. Finally, we discuss our findings and draw conclusions.

\section{Literature Background}

\subsection{Quality concerns in outsourcing practices of supply chains}

Since the late $20^{\text {th }}$ century, outsourcing has become an inextricable part of strategic decisions made by global companies to achieve cost reduction, increased productivity, and enhanced quality (Gray et al., 2009; J. Chen et al., 2015). Outsourcing practices range from activities associated with managing information technology and business processes to the actual manufacturing and production of goods or services (Steven et al., 2014; Gunasekaran et al., 2015). Moreover, outsourcing decisions vary substantially from out-tasking to fulloutsourcing (for more information see, Sanders et al., 2007), which makes outsourcing a flexible and preferred choice by both manufacturing and service companies for diverse outsourcing strategies.

However, there are downsides to outsourcing practices adopted by companies amongst which quality concerns of downstream and/or upstream supply chain members and lack of control over these members play a critical role (Kaya \& Özer, 2009; Xiao et al., 2014). As supply chains extend their outsourcing practices, the low visibility of their suppliers' or distributors' processes could lead to quality issues such as substandard quality of material, nonconformity to manufacturing specifications, and poor goods maintenance of in logistics operations, for example (Yang et al., 2009; Tse \& Tan, 2012).

Despite the abundance of research focusing on quality management issues within an individual firm or entity (Sousa \& Voss, 2002), literature on quality issues of outsourcing in 
the context of supply chains is scarce (Robinson \& Malhotra, 2005; Kouvelis et al., 2006; Steven et al., 2014). Recent investigations into supply chain quality management has focused on managing the quality of contract manufacturers and the impact of facility audits and contractual penalties (Handley \& Gray, 2013). Several outsourcing decisions such as make-orbuy decisions, offshoring, offshore product relocation and supply base consolidation on quality of product recalls have been investigated across several industries (Steven et al., 2014). The applications of various analytical models, such as game theory, for strategic outsourcing decisions of competing buyers for quality improvement and quality competition, have also been investigated (Bae et al., 2009; Xiao et al., 2014).

Managing organizational performance can significantly enhance quality of services and products delivered by supply chains. The truism that you cannot manage what you cannot measure is especially pertinent when it comes to performance measurement and quality (Adams et al., 1995). This statement is valid and even more important across the supply chain due to the complex nature of interrelations between and amongst supply chain members (Bai \& Sarkis, 2012). Given that quality of goods and services in supply chains is dependent on effective performance measurement, in this study we specifically focus on performance criteria in service outsourcing. The case study for testing the applicability of the proposed model sets the foundation for performance effectiveness and quality services in a banking setting.

Assessing the performance of outsourcers in general has been hitherto subject to various studies, proposing different performance metrics and analytical frameworks to this end (e.g., Bustinza et al., 2010; Feng et al., 2011; Kenyon et al., 2016). Outsourcing has also been viewed through the prism of various theoretical backgrounds (e.g., Ellram et al., 2008; McIvor, 2009). Based on the recent exemplary review of the literature by Gunasekaran et al. (2015), the performance metrics in outsourcing could be classified according to the outsourcing phase (pre/during-/post-outsourcing stage) and the type of the performance metrics, which in turn could 
be monetary or non-monetary. Reviewing the performance measurement models in outsourcing, Gunasekaran et al. (2015) enumerate a wide range of tools and techniques from game-theoretic related models to multi-criteria decision analysis and decision support system tools. As part of their suggestions for future research, Gunasekaran et al. (2015) invite researchers to develop "suitable mathematical [and simulation] models" with the purpose of analyzing outsourcing decisions. They call for models that could prioritize the exiting outsourcing criteria for both outsourcers and the outsourced companies. This requires an analytical model that is capable of measuring outsourcing performance at the level of supply chain tiers and the supply chain system as a whole.

By shifting the attention from manufacturing outsourcing, services outsourcing has been growing substantially for the past two decades (Caniato et al., 2015; Perdikaki et al., 2015). However, there have been controversies regarding the efficiency of outsourcing in service supply chains, increasing sensitivity towards applying solutions for improving the quality of their outsourcing practices (Ellram et al., 2007). The main issue revolving around services outsourcing and offshoring include loss of knowledge and understanding of the outsourced operations, hence limiting the ability of the outsourcer to evaluate upstream or downstream supply chain members and their quality (Ellram et al., 2008). There have been calls for more investigations on services outsourcing (Roth \& Menor, 2003). Studies addressing certain aspects to this issue do exist (e.g., Bardhan \& Kroll, 2003; Farrell et al., 2006; Lewin \& Peeters, 2006; Feng et al., 2011; Caniato et al., 2015). But, the literature still lacks a model and methodology explicating the dynamics of outsourcing and especially services outsourcing for measuring performance in supply chains (Gunasekaran et al., 2015). Helping to fill this gap, we address some of these performance and quality concerns in the services outsourcing supply chain environment. 


\section{Analytical Model}

\subsection{Network DEA combined with the SBM approach}

Since the introduction of data envelopment analysis (DEA) (Charnes et al., 1978) numerous studies have been conducted based on DEA and its combinations with various mathematical and/or statistical models to measure relative efficiency of decision making units (DMUs) (see Cook \& Seiford, 2009; Liu et al., 2013b, 2013a). DEA is a multiple input/multiple output analytical model that is capable of comparing several entities/decision making units (DMUs) (i.e. supply chains in this context) based on their performance according to the values of the inputs/outputs. DEA uses a Pareto frontier marked by one or several DMU(s) to rank other DMUs accordingly. Using the DEA modelling, a linear programming model per each DMU is solved according to the values for inputs and outputs. This process will assign weights to each linear aggregation and the DMUs that constitute the Pareto frontier are chosen based on the assumption that, given the same weights, no other DMU except for the Pareto frontier, will have the efficiency of above $100 \%$. Thus the Pareto frontier in DEA models is defined by efficient DMUs. A more detailed account of how this is done is provided by Adler et al. (2002). However, conventional DEA methods treat the systems under investigation as a black box with no further insights into the efficiency of sub-processes within those systems.

To seek transparency into the black box, efficiency of sub-processes were investigated Fare (1991), while some DEA research sought to simultaneously consider both system and subprocess efficiencies (Sarkis \& Talluri, 1996; Kao \& Hwang, 2008). Part of this investigation involved the utilization of network DEA models.

Network DEA has been applied to a variety of contexts from performance measurement in mostly the banking industry (Akther et al., 2013; Matthews, 2013) to other industrial and services sectors (Mirhedayatian et al., 2014; You \& Jie, In press). Despite its advantages, the 
application of network DEA models in supply chain performance assessment has been limited to a few studies (C. Chen \& Yan, 2011; Mirhedayatian et al., 2014), which are all associated with manufacturing supply chains rather than service supply chains.

Whereas early DEA models focused on radial approaches to evaluate efficiency (e.g. BCC and CCR models), the SBM approach was later recommended to improve DEA discrimination power (Tone \& Tsutsui, 2009). SBM also enables network DEA models to account for weakly efficient DMUs. SBM is a suitable approach where the changes in inputs and outputs are nonproportionate. SBM also allows inputs and outputs of different units of measurement to be incorporated in the DEA model (Cooper et al., 2006). In supply chains, this feature of SBM allows analysts the latitude to include data with different units of measurement in one SBMbased network DEA model. Recently, there has been growing interest among operations researchers to adopt the SBM approach in network DEA for different industrial and services contexts due to its accuracy and flexibility (see among, Fukuyama \& Mirdehghan, 2012; Akther et al., 2013; Matthews, 2013; Kao, 2014a).

The application of network DEA models are mostly limited to closed systems in which all the variables are known to evaluate the DMUs. Systems in practical settings, supply chains and global supply chains in particular, where outsourcing practices occur, include different players with complex and large numbers of measures and metrics to manage. To this end, Chang et al. (2014) proposed the ownership-specified network DEA models. These models introduced input-oriented and output-oriented network DEA models for three types of centralized, distributed, and hybrid network structures. Different proportions of processes were assigned to internal and external entities in supply chains. Integrating hybrid network DEA with variable returns-to-scale and SBM, we discuss how the performance of an outsourcer could be evaluated in supply chains by considering all the input and output processes from both internal and external entities within that supply chain. 


\subsection{Model development}

This section presents the analytical model developed to evaluate performance in supply chains with processes related to internal entities, such as divisions, branches, subsidiaries, and to external entities such as suppliers, distributors, wholesalers as hybrid networks (see Figure 1). SBM with variable returns-to-scale (Tone \& Tsutsui, 2009; Kao, 2014a) is used to enable network DEA models to identify weakly efficient DMUs. The hybrid network modeling approach (Chang et al., 2014) is adopted to incorporate exogenous and endogenous inputs and outputs associated with all the processes in a given supply chain. As previously discussed, one of the main concerns of outsourcing in supply chains is information loss and information asymmetry between tiers in supply chains (Ellram et al., 2008; Handley \& Gray, 2013). In reality, it is unlikely for the outsourcer to have access to complete supplier information (inputs and outputs). Chang et al. (2014) proposed ownership-specified network DEA models for such hybrid networks. We subsequently combine this model with general SBM for network systems (Kao, 2014a) providing a more accurate estimation and increased discrimination power of efficiency scores for outsourcers and their supply chains.

The notation and indices are provided in Table 1.

\section{Table 1}

Notations.

$i=$ Numerator index corresponding to exogenous inputs

$r=$ Numerator index corresponding to exogenous outputs

$f=$ Numerator index corresponding to endogenous inputs

$g=$ Numerator index corresponding to endogenous outputs

$J=$ Set of DMUs

$K=$ Set of all processes for both external and internal entities

$K_{I}=$ Set of processes for internal entities

$K_{E}=$ Set of processes for external entities

$I^{\left(k_{I}\right)}=$ Set of exogenous inputs for $k_{I}$

$O^{\left(k_{I}\right)}=$ Set of exogenous outputs for $k_{I}$

$M^{\left(k_{I}\right)}=$ Set of endogenous inputs for $k_{I}$

$N^{\left(k_{I}\right)}=$ Set of endogenous outputs for $k_{I}$ 


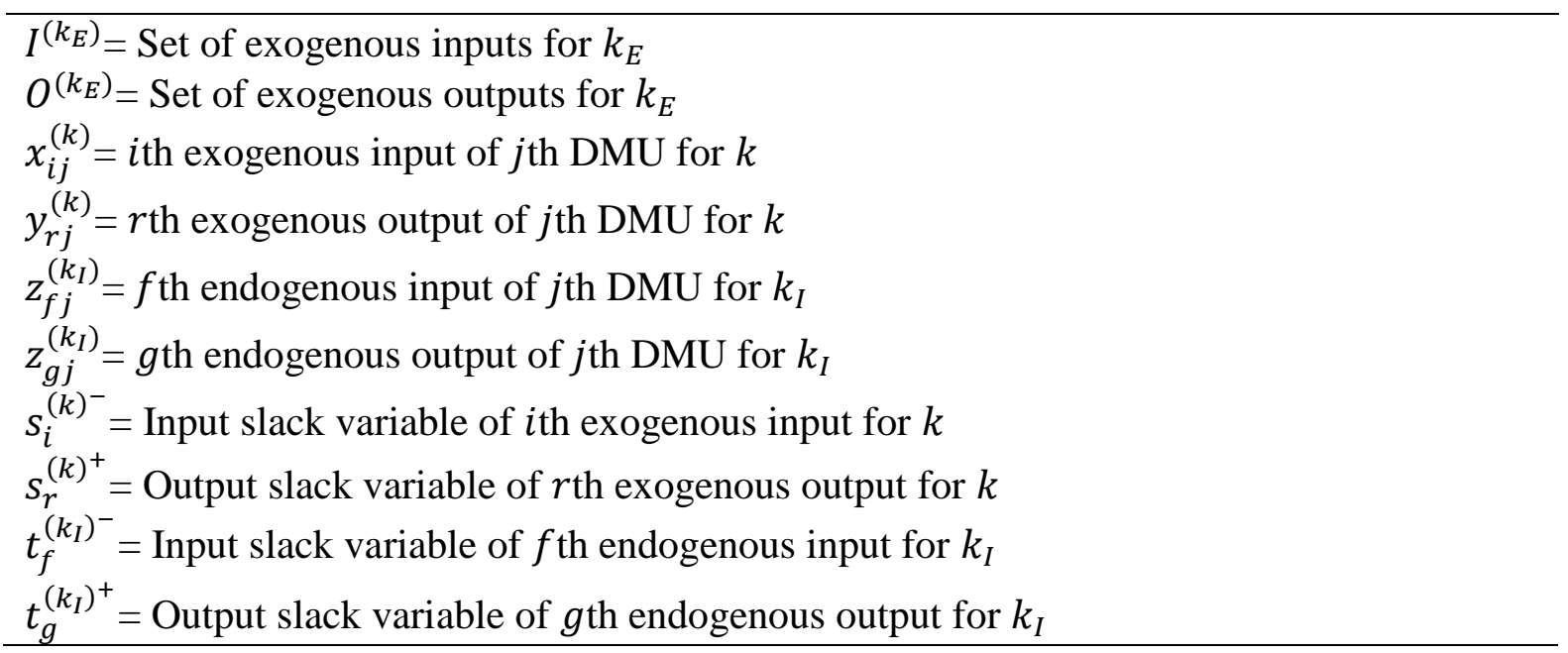

Hybrid networks are usually comprised of a total number of $|K|$ entities with a set of $\left|K_{I}>1\right|$ internal entities and $\left|K_{E} \geq 1\right|$ external entities such that $K_{I} \cup K_{E}=K$ and $K_{I} \cap K_{E}=$ $\varnothing$ (Chang et al., 2014). In these networks, the main manufacturer or service provider (i.e., outsourcer) has complete control over the processes of its internal entities, while this control is only partial when dealing with external entities such as suppliers or distributors under certain contractual agreements. Usually, the only known parameters to the outsourcer are the endogenous inputs and outputs received from or sent to the supplier in exchange for payments for the goods or services provided by the supplier (i.e. exogenous inputs to supplier). However, accessibility of the outsourcer to the information related to the supplier's extra outputs is highly unlikely. Thus, exogenous outputs $\left(Y_{r j}^{(k)}\right)$ produced by suppliers $\left(K_{E}\right)$ in Figure 1 are illustrated by dotted lines indicating their inaccessibility. It is assumed that an outsourcer's knowledge of the exogenous inputs of processes for external entities is only partial. Thus unlike the exogenous outputs, known exogenous inputs of external entities that directly relate to outsourcing practices are included in the model (Chang et al., 2014). The model can be extended to include downstream external entities as well, but the focus of this article is on the upstream relationships and outsourcing. 
External entities

Internal entities

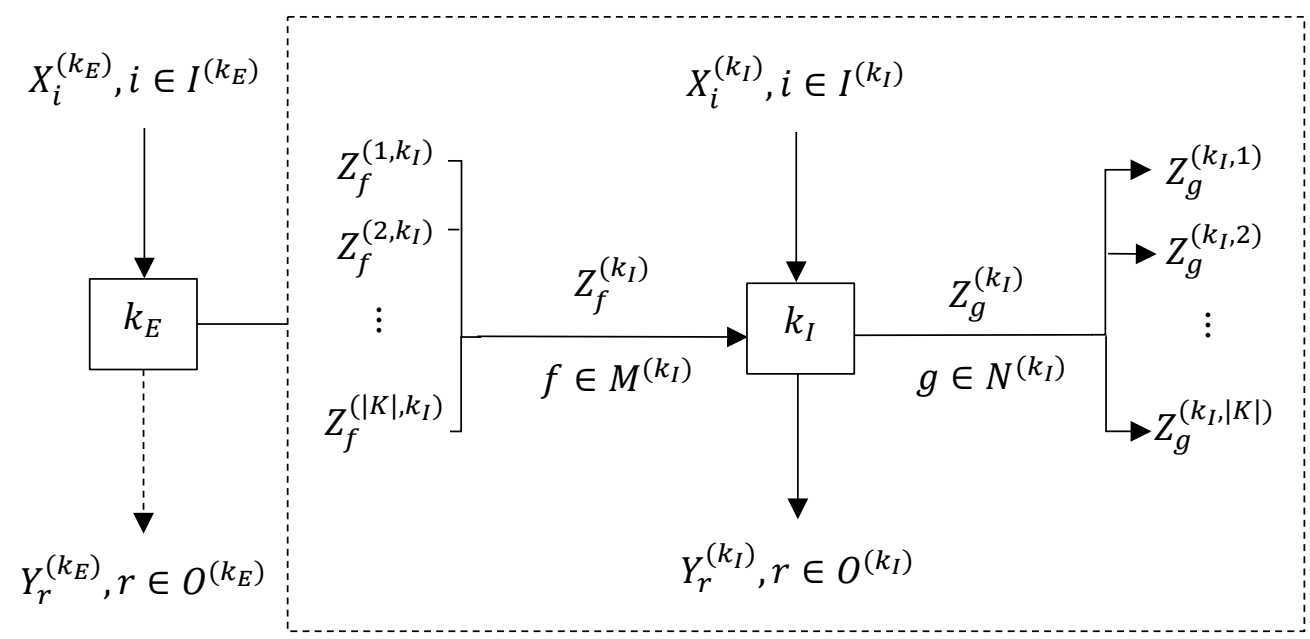

Figure 1. Supply chain outsourcing model with internal and external entities

Referencing Figure 1 , let $X_{i}^{(k)}, i \in I^{(k)}$ be the exogenous inputs and $Z_{f}^{\left(k_{I}\right)}, f \in M^{\left(k_{I}\right)}$ the endogenous inputs utilized by either one of the internal or external entities in a supply chain to produce endogenous outputs $Z_{g}^{\left(k_{I}\right)}, g \in N^{\left(k_{I}\right)}$ used by downstream internal or external entities to produce the exogenous outputs $Y_{r}^{\left(k_{I}\right)}, r \in O^{\left(k_{I}\right)}$. The production probability set $P=$ $\{(x, y, z)\}$ of this network is defined as (Fare et al., 1996; Fare \& Grosskopf, 2000):

$$
\begin{aligned}
& \sum_{j=1}^{n} \lambda_{j}^{(k)} X_{i j}^{(k)} \leq x_{i}^{(k)}\left(i \in I^{(k)} ; \forall k \in K\right), \\
& \sum_{j=1}^{n} \lambda_{j}^{(k)} Z_{f j}^{(k)} \leq z_{f}^{(k)}\left(f \in M^{(k)} ; \forall k \in K_{I}\right), \\
& \sum_{j=1}^{n} \lambda_{j}^{(k)} Z_{g j}^{(k)} \geq z_{g}^{(k)}\left(g \in N^{(k)} ; \forall k \in K_{I}\right), \\
& \sum_{j=1}^{n} \lambda_{j}^{(k)} Z_{g j}^{(k)}=\sum_{j=1}^{n} \lambda_{j}^{(k+1)} Z_{f j}^{(k)}\left(g \in N^{(k)} ; f \in M^{(k+1)} ; \forall k \in K_{I}\right), \\
& \sum_{j=1}^{n} \lambda_{j}^{(k)} Y_{r j}^{(k)} \geq y_{r}^{(k)}\left(r \in O^{(k)} ; \forall k \in K_{I}\right), \\
& \sum_{j=1}^{n} \lambda_{j}^{(k)}=1(\forall k \in K), \\
& \lambda_{j}^{(k)} \geq 0(\forall j \in J ; \forall k \in K)
\end{aligned}
$$


where $\lambda_{j}^{(k)}, j \in J$ is the intensity factor corresponding to the $k$ th process $k \in K$. Equation (1f) implies variable returns-to-scale (Banker et al., 1984). Equations (1a) and (1b) represent feasible exogenous and endogenous inputs for process $k, \forall k \in K$ to be greater than or equal to the convex hull of the existing exogenous and endogenous inputs for that process. Any feasible exogenous outputs for internal entities and endogenous outputs for the processes of all entities in equations (1c) and (1e) should be less than the convex hull of the respective exogenous and endogenous outputs for their respective process. Equation (1d) ensures that continuity of flows between two consecutive processes is maintained, which means that all intermediate products by process $k$ are utilized by process $k+1, \forall k \in K$. It should be noted that based on expression (1e), only exogenous outputs of internal entities known to the outsourcer in its internal processes are needed; thus eliminating unknown exogenous outputs by other members of the supply chain.

Using the general SBM for network DEA models (Kao, 2014a) and the hybrid network DEA model (Chang et al., 2014) in a single model, system efficiency of $\mathrm{DMU}_{o}$ can be formulated as:

$$
\begin{aligned}
& E_{o}=\min \frac{\sum_{k=1}^{|K|}\left[1-\left(\sum_{i \in I^{(k)}} \frac{s_{i}^{(k)^{-}}}{X_{i o}^{(k)}}+\sum_{f \in M^{\left(k_{I}\right)}} \frac{t_{f}^{\left(k_{I}\right)^{-}}}{Z_{f o}^{\left(k_{I}\right)}}\right) /\left(\hat{l}^{(k)}+\hat{m}^{\left(k_{I}\right)}\right)\right]}{\sum_{k=1}^{|K|}\left[1+\left(\sum_{r \in O^{\left(k_{I}\right)}} \frac{s_{r}^{\left(k_{I}\right)^{+}}}{Y_{r p}^{\left(k_{I}\right)}}+\sum_{g \in N^{\left(k_{I}\right)}} \frac{t_{g}^{\left(k_{I}\right)^{+}}}{Z_{g o}^{\left(k_{I}\right)}}\right) /\left(\hat{o}^{\left(k_{I}\right)}+\hat{n}^{\left(k_{I}\right)}\right)\right]} \\
& \sum_{j=1}^{n} \lambda_{j}^{(k)} X_{i j}^{(k)}+s_{i}^{(k)^{-}}=x_{i o}^{(k)}\left(i \in I^{(k)} ; \forall k \in K\right), \\
& \sum_{j=1}^{n} \lambda_{j}^{\left(k_{I}\right)} Z_{f j}^{\left(k_{I}\right)}+t_{f}^{\left(k_{I}\right)^{-}}=z_{f o}^{\left(k_{I}\right)}\left(f \in M^{\left(k_{I}\right)} ; \forall k_{I} \in K_{I}\right), \\
& \sum_{j=1}^{n} \lambda_{j}^{\left(k_{I}\right)} Z_{g j}^{\left(k_{I}\right)}-t_{g}^{\left(k_{I}\right)^{+}}=z_{g o}^{\left(k_{I}\right)}\left(g \in N^{\left(k_{I}\right)} ; \forall k_{I} \in K_{I}\right), \\
& \sum_{j=1}^{n} \lambda_{j}^{\left(k_{I}\right)} Z_{g j}^{\left(k_{I}\right)}=\sum_{j=1}^{n} \lambda_{j}^{\left(k_{I}+1\right)} Z_{f j}^{\left(k_{I}\right)}\left(g \in N^{\left(k_{I}\right)} ; f \in M^{\left(k_{I}+1\right)} ; \forall k_{I} \in K_{I}\right), \\
& \sum_{j=1}^{n} \lambda_{j}^{\left(k_{I}\right)} Y_{r j}^{\left(k_{I}\right)}-s_{r}^{\left(k_{I}\right)^{+}}=y_{r o}^{\left(k_{I}\right)}\left(r \in O^{\left(k_{I}\right)} ; \forall k \in K_{I}\right), \\
& \sum_{j=1}^{n} \lambda_{j}^{(k)}=1(\forall k \in K),
\end{aligned}
$$




$$
\begin{aligned}
\lambda_{j}^{(k)} \geq 0, s_{i}^{(k)^{-}} & \geq 0, t_{f}^{\left(k_{I}\right)^{-}} \geq 0, t_{g}^{\left(k_{I}\right)^{+}} \geq 0, s_{r}^{\left(k_{I}\right)^{+}} \geq 0\left(\forall j \in J ; \forall k \in K ; \forall k_{I} \in K_{I} ; i\right. \\
& \left.\in I^{(k)} ; f \in M^{\left(k_{I}\right)} ; g \in N^{\left(k_{I}\right)} ; r \in O^{\left(k_{I}\right)}\right)
\end{aligned}
$$

where $s_{i}^{(k)^{-}}\left(\forall k \in K ; i \in I^{(k)}\right), t_{f}^{(k)^{-}}\left(\forall k_{I} \in K_{I} ; f \in M^{\left(k_{I}\right)}\right), t_{g}^{(k)^{+}}\left(\forall k_{I} \in K_{I} ; g \in N^{\left(k_{I}\right)}\right)$, $s_{r}^{\left(k_{I}\right)^{+}}\left(\forall k_{I} \in K_{I} ; r \in O^{\left(k_{I}\right)}\right)$ are slack variables associated with (2b), (2c), (2d), and (2f), respectively. Additionally, $\hat{\imath}^{(k)}, \widehat{m}^{\left(k_{I}\right)}, \hat{o}^{\left(k_{I}\right)}$, and $\hat{n}^{\left(k_{I}\right)}$ represent the number of indices in $I^{(k)}$, $M^{\left(k_{I}\right)}, O^{\left(K_{I}\right)}$, and $N^{\left(k_{I}\right)}$, respectively.

The slack variables associated with endogenous inputs and outputs are included in system efficiency objective (2a) (Fukuyama \& Mirdehghan, 2012; Kao, 2014a). Unlike the traditional SBM approach (Tone \& Tsutsui, 2009), there is no need to insert the weight of processes in equation (2a) (Kao, 2014a). Whereas (2a)-(2h) provide a set of weights for each process in a given DMU by defining the process weights as the ratio of output efficiency score of each of the processes over the sum of all other processes in the system. Thus, we ascertain that all the defined weights are positive and they add up to one, as a requirement for the system efficiency being the weighted average of the efficiency of its sub-processes. Hence, upon solving (2a)(2h) and obtaining optimal solutions for $s_{i}^{(k)^{-^{*}}}, t_{f}^{\left(k_{I}\right)^{-^{*}}}, s_{r}^{\left(k_{I}\right)^{+^{*}}}$, and $t_{g}^{\left(k_{I}\right)^{+^{*}}}$ system efficiency and process efficiency for $\mathrm{DMU}_{o}$ can be formulated as:

$$
\begin{aligned}
& E_{o}=\frac{\sum_{k=1}^{|K|}\left[1-\left(\sum_{i \in I^{(k)}} \frac{s_{i}^{(k)^{-^{*}}}}{X_{i o}^{(k)}}+\sum_{\left.f \in M^{\left(k_{I}\right.}\right)} \frac{t_{f}^{\left(k_{I}\right)^{-*}}}{Z_{f o}^{\left(k_{I}\right)}}\right) /\left(\hat{\imath}^{(k)}+\widehat{m}^{\left(k_{I}\right)}\right)\right]}{\sum_{k=1}^{|K|}\left[1+\left(\sum_{r \in O^{\left(k_{I}\right)}} \frac{s_{r}^{\left(k_{I}\right)^{+^{*}}}}{Y_{r p}^{\left(k_{I}\right)}}+\sum_{\left.g \in N^{(} k_{I}\right)} \frac{t_{g}^{\left(k_{I}\right)^{+^{*}}}}{Z_{g o}^{\left(k_{I}\right)}}\right) /\left(\hat{o}^{\left(k_{I}\right)}+\hat{n}^{\left(k_{I}\right)}\right)\right]} \\
& E_{o}^{(k)}=\frac{1-\left(\sum_{i \in I^{(k)}} \frac{s_{i}^{(k)^{-*}}}{X_{i o}^{(k)}}+\sum_{f \in M^{\left(k_{I}\right)}} \frac{t_{f}^{\left(k_{I}\right)^{-^{*}}}}{Z_{f o}^{\left(k_{I}\right)}}\right) /\left(\hat{\imath}^{(k)}+\widehat{m}^{\left(k_{I}\right)}\right)}{1+\left(\sum_{r \in O^{\left(k_{I}\right)}} \frac{s_{r}^{\left(k_{I}\right)^{+^{*}}}}{Y_{r p}^{\left(k_{I}\right)}}+\sum_{g \in N^{(k)}} \frac{t_{g}^{\left(k_{I}\right)^{+*}}}{Z_{g o}^{\left(k_{I}\right)}}\right) /\left(\hat{o}^{\left(k_{I}\right)}+\hat{n}^{\left(k_{I}\right)}\right)}\left(\forall k \in K ; \forall k_{I} \in K_{I}\right),
\end{aligned}
$$


Chang et al. (2014) argue that due to the lack of information about the processes in external entities, reporting their efficiency scores using equation (3b) is not recommended. However, these external entities and their interaction with the internal entities in supply chains should be considered for evaluating the performance of the outsourcer and obtaining the overall supply chain efficiency. This is achieved in our proposed models (2a-2h) and (3a-3b) by incorporating the relevant inputs/outputs of suppliers, as external entities, to outsourcer's operations.

\section{A Case Study from the Banking Industry}

The service industry deals directly with customers. Quality is immediate and can have an instant effect on the bottom line of service settings. An important aspect of quality in service industry is making sure that efficient and timely service is provided. Thus, efficiency of processes, whether internal or outsourced is a major driver for quality.

We consider a service supply chain comprised of a commercial bank and its subdivisions as internal entities and operations related to an investment bank collaborating with the commercial bank as an external entity. Commercial banks provide a variety of banking services such as loans and other credit products, trade finance, specialized employer and cash management services, and corporate financing through issuing and underwriting bonds. Services provided to commercial banks’ corporate customers through their corporate banking division fall into two main categories, interest-bearing and non-interest bearing services (Avkiran, 2015). While lending and revenues obtained from loans are the main function of the interest-bearing services, commissions from other financial services such as bonds underwriting and issuing services constitute a commercial bank’s main non-interest revenues. Figure 2 illustrates the service supply chain of commercial banks as outsourcers of certain financial services to external investment banks. 
A commercial banking performance model is adopted for this study Avkiran (2015). A single financial period is used to assign inputs and outputs on Non-interest operations and Interest-bearing operations divisions, which will be considered internal entities of the service supply chain. Sometimes commercial banks collaborate with or outsource certain financial services to external investment banks, especially for large financing projects. Outsourcing expenses, such as commissions, costs of quality of services, and supervisory costs, could be considered exogenous inputs. Net value of services provided is the endogenous output of the external investment bank for the commercial bank.

A variety of financial and non-financial performance measurement criteria in the supply chain literature for evaluating the quality of outsourcing exist (Gunasekaran et al., 2015). In this study we rely on the well-established frameworks proposed for bank efficiency assessment in the DEA literature to ensure the validity of the performance metrics (Fethi \& Pasiouras, 2010).

The performance metrics in this model include good and bad outputs. For example Proportion of fruitless referrals and Non-performing loans ratios may be outcomes that are perceived as bad outputs and can be treated as inputs in the formulation of the model in (2a)(2h) (Thanassoulis et al., 2008; Avkiran, 2015). 
Investment bank

(Supplier - external entity)
Commercial bank

(Outsourcer - internal entity)

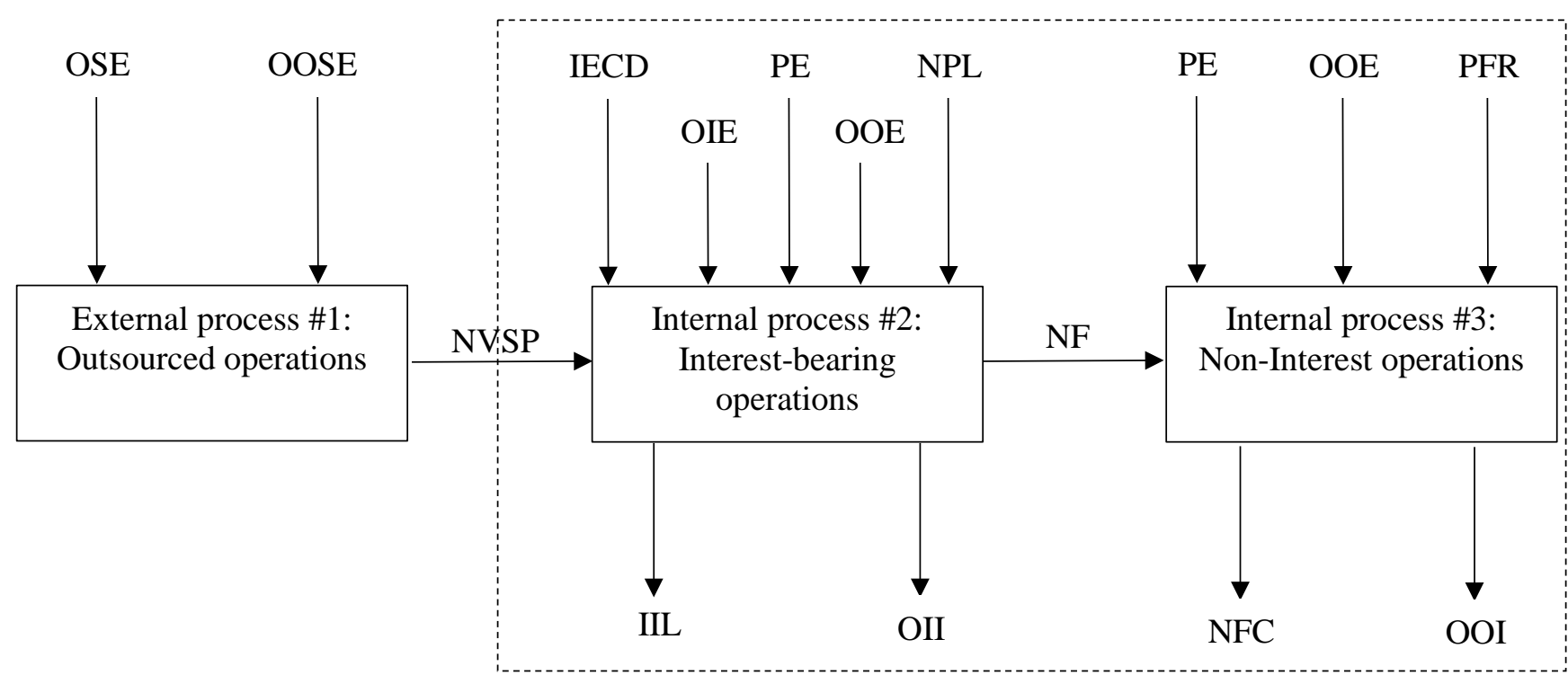

Figure 2. Service supply chain of commercial banks with two internal entities and one external entity. Legend: OSE (outsourcing expenses), OOSE (other outsourcing expenses), NVSP (net value of services provided), IECD (interest expense on customer deposits), OIE (other interest expenses), PE (personnel expense), OOE (other operating expense), NPL (non-performing loans ratio), IIL (interest income on loans), OII (other interest income), NF (number of referrals), PFR (proportion of fruitless referrals), NFC (net fees and commissions), OOI (other operating income).

The context of the case study is commercial banks’ service supply chains in Iran. Iran’s less-investigated banking and financial market has recently drawn attention of foreign investors. The Iranian banking system plays an important role in providing financial services to different industrial and service sectors in this country. Iran started introducing private banks to its financial market in the late 1990s. Over the past decade, in addition to some newly established private banks, shares of former public banks, such as Mellat and Tejarat, have been offered on the Tehran Stock Exchange. Currently, eight public banks, 21 private banks and six other financial and credit institutions are active in Iran's financial market. According to the reports published by regulatory bodies in Iran, by November 2013 the value of loans to individuals and commercial customers for private banks alone extended 46 billion USD, which is a significant amount given Iran's economy. However, despite their significance, private 
banks are performing weaker than public banks in converting deposits to loans. Moreover, private banks have a relatively smaller share of deposits than public banks but perform better in the domains of online and mobile banking. Since 2007 and after the introduction of universal banking systems in Iran, private sector commercial banks have made significant advancements in the variety and quality of services they provide.

Given a highly competitive environment where banks seek to acquire larger market share, public and private commercial banks in Iran look for ways to best estimate the efficiency of their sub-divisions and their collaborating suppliers that include other investment banks and financial institutions.

Data for this study is acquired through the use of archival data published in the periodical reports of the Central Bank of Iran, Annual Review, and through field study visits to commercial banks' information and customer service centers. The data collection focused on the sets of inputs and outputs necessary for the model as defined in Figure 2. Table 2 summarizes the descriptive statistics of the exogenous and endogenous inputs and outputs used in this study. A total of 28 public and private commercial banks in Iran had data that could be used in the analysis. MATLAB 2014b was used to code and execute the models (2a-2h) and (3a-3b). 
Table 2

Descriptive statistics of exogenous and indigenous inputs and outputs for financial year 2013-2014 ${ }^{\mathrm{a}}$

\begin{tabular}{lcllll}
\hline & Factor & Mean & $\begin{array}{l}\text { Standard } \\
\text { Deviation }\end{array}$ & Minimum & Maximum \\
\hline $\begin{array}{l}\text { Outsourced operations (External } \\
\text { process \#1) }\end{array}$ & & & & & \\
Outsourcing expenses & $x_{1 j}^{1}$ & 13.314 & 7.499 & 5.999 & 23.793 \\
Other outsourcing expenses & $x_{2 j}^{1}$ & 6.278 & 2.997 & 4.339 & 10.748 \\
Net value of services provided & $z_{1 j}^{1}$ & 20.099 & 3.067 & 16.217 & 23.582 \\
Interest-bearing operations (internal & & & & & \\
process \#2) & & & & & \\
Interest expenses on consumer deposits & $x_{1 j}^{2}$ & 109.601 & 16.039 & 88.523 & 125.860 \\
Other interest expenses & $x_{2 j}^{2}$ & 46.823 & 10.468 & 33.709 & 58.593 \\
Personnel expenses & $x_{3 j}^{2}$ & 35.689 & 11.429 & 20.091 & 47.357 \\
Other operating expenses & $x_{4 j}^{2}$ & 48.009 & 6.594 & 33.664 & 63.966 \\
Non-performing loans ratio & $x_{5 j}^{2}$ & 0.051 & 0.030 & 0.225 & 0.091 \\
Interest income on loans & $y_{1 j}^{2}$ & 456.596 & 127.486 & 331.136 & 578.740 \\
Other interest income & $y_{2 j}^{2}$ & 133.915 & 39.278 & 91.162 & 168.683 \\
Number of referrals & $z_{1 j}^{2}$ & 83.625 & 18.065 & 61.250 & 101.500 \\
Non-interest operations (internal & & & & & \\
process \#3) & & & & & \\
Personnel expenses & $x_{1 j}^{3}$ & 26.284 & 7.096 & 17.593 & 32.222 \\
Other operating expenses & $x_{2 j}^{3}$ & 42.129 & 9.498 & 30.715 & 52.418 \\
Proportion of fruitless referrals & $x_{3 j}^{3}$ & 0.087 & 0.014 & 0.071 & 0.105 \\
Net fees and commissions & $y_{1 j}^{3}$ & 36.604 & 10.087 & 22.383 & 46.207 \\
Other operating income & $y_{2 j}^{3}$ & 19.444 & 3.874 & 14.050 & 23.116 \\
\hline Fing & & & & & \\
\hline
\end{tabular}

${ }^{a}$ Financial data is in USD million.

\section{Results and Discussion}

Parametric and non-parametric statistical tests for the efficiency scores obtained by the model presented in Section 3 are summarized in Table 3. The results show that commercial banks of the public sector are equally efficient as the private sector in their overall efficiency and non-interest operations efficiency (i.e. Internal process \#3). However, a significant gap in the efficiency of the interest-bearing operations (i.e. Internal process \#2) is observed when comparing public and private banks. Public banks for internal process \#2 show better performance. This result implies a higher ratio of interest income to expenses for public banks. 
The statistically significant lower mean for private commercial banks interest-bearing operations efficiency scores are likely caused by newly-established private banks such as Khavarmianeh and Ansar banks.

As previously discussed, investment bank efficiency scores (i.e. External process \#1) were not included since banks, as outsourcers, did not have enough access to all the financial criteria required to conduct a holistic evaluation of those external entities. However, investment bank impact on commercial bank performance is evaluated through the commissions and other operational expenses investment banks charged commercial banks for services they provided. 


\section{Table 3}

Efficiency scores for the overall service supply chain and for internal processes

\begin{tabular}{|c|c|c|c|c|c|}
\hline No. & DMU & $\begin{array}{l}\text { Overall } \\
\text { supply } \\
\text { chain } \\
\text { efficiency }\end{array}$ & Rank & $\begin{array}{l}\text { Efficiency } \\
\text { of internal } \\
\text { process } \\
\# 2\end{array}$ & $\begin{array}{l}\text { Efficiency } \\
\text { of internal } \\
\text { process } \\
\# 3\end{array}$ \\
\hline & Public commercial banks & & & & \\
\hline 1 & Sepah & 0.774 & 21 & 0.862 & 0.799 \\
\hline 2 & Post Bank & 0.837 & 20 & 0.696 & 0.903 \\
\hline 3 & Melli Iran & 1 & 1 & 1 & 1 \\
\hline 4 & Tose-e-Saderat & 0.967 & 17 & 0.956 & 0.877 \\
\hline 5 & Sanat-va-Madan & 0.739 & 22 & 0.909 & 0.684 \\
\hline 6 & Keshavarzi & 1 & 1 & 1 & 1 \\
\hline 7 & Maskan & 1 & 1 & 1 & 1 \\
\hline \multirow[t]{4}{*}{8} & Tose-e-Taavon & 0.988 & 16 & 0.962 & 0.967 \\
\hline & Mean for public banks & 0.913 & & 0.923 & 0.904 \\
\hline & Number of efficient public banks & 3 & & 3 & 3 \\
\hline & Private commercial banks & & & & \\
\hline 1 & Eghtesad Novin & 1 & 1 & 1 & 1 \\
\hline 2 & Parsian & 1 & 1 & 1 & 1 \\
\hline 3 & Kaar Afarin & 0.995 & 14 & 1 & 0.947 \\
\hline 4 & Saman & 0.937 & 19 & 0.844 & 0.981 \\
\hline 5 & Pasargad & 1 & 1 & 1 & 1 \\
\hline 6 & Sarmaye & 1 & 1 & 1 & 1 \\
\hline 7 & Sina & 1 & 1 & 1 & 1 \\
\hline 8 & Shahr & 0.993 & 15 & 0.974 & 1 \\
\hline 9 & Day & 0.683 & 23 & 0.755 & 0.605 \\
\hline 10 & Ansar & 0.573 & 26 & 0.229 & 0.590 \\
\hline 11 & Tejarat & 1 & 1 & 1 & 1 \\
\hline 12 & Refah-e-Kargaran & 0.960 & 18 & 0.936 & 0.845 \\
\hline 13 & Saaderate-e-Iran & 0.683 & 23 & 0.558 & 0.836 \\
\hline 14 & Mellat & 1 & 1 & 1 & 1 \\
\hline 15 & Hekmat-e-Iranian & 1 & 1 & 1 & 1 \\
\hline 16 & Gardeshgari & 0.388 & 27 & 0.598 & 0.221 \\
\hline 17 & Iran Zamin & 0.630 & 25 & 0.988 & 0.452 \\
\hline 18 & Ghavamin & 1 & 1 & 1 & 1 \\
\hline 19 & Khavarmianeh & 0.206 & 28 & 0.500 & 0.680 \\
\hline \multirow[t]{7}{*}{20} & Ayandeh & 1 & 1 & 1 & 1 \\
\hline & Mean for private banks & 0.852 & & 0.847 & 0.867 \\
\hline & Number of efficient private banks & 10 & & 11 & 12 \\
\hline & T-test (p-value, two-tailed) & 0.681 & & 2.613 & 0.557 \\
\hline & & 79 & & 15 & 71.5 \\
\hline & Mann-Whitney U (Prob > X², one-tailed) & $(0.481)$ & & $(0.000)^{*}$ & $(0.326)$ \\
\hline & Wilcoxon W (Prob > X², one-tailed) & 115 & & 51 & 107.5 \\
\hline
\end{tabular}

* Significant at 0.05 level. 
Figures 3 and 4 graphically illustrate the differences between public and private bank overall efficiency scores and efficiency scores of internal processes \#2 and \#3, respectively. There is no direct pattern in differences, where the overall efficiency score for a commercial bank's service supply chain is higher than the efficiency scores of its sub-processes in some cases, whereas in others it is lower. These inconsistencies could be traced back to the role of the external entities, such as the investment bank in this example. In some cases such as Tosee-Taavon bank (labeled '8' in Figure 3) efficiency in the processes of the external investment bank has resulted in an overall higher efficiency score of the bank's supply chain compared to the efficiency of its internal processes. In other cases such as Sepah bank (labeled ' 1 ' in Figure 3), an opposite result was observed; where overall efficiency score has suffered from inefficiencies in the operations of its investment bank. One of the possible causes of this inefficiency could be traced back to comparatively higher amounts of expenditure made to provide the same value of services by investment banks for the commercial banks. Thus, although no direct patterns existed, banks can complete a relative analysis of how outsourced activities have affected the efficiency, and quality, of their performance. One way of doing this is to evaluate overall efficiency versus internal process efficiency, where higher overall efficiencies when compared to internal efficiencies, implying better outsourcing quality performance.

The same pattern could be observed for private commercial banks’ service supply chains. For instance, while Refah-e-Kargaran bank (labeled '12' in Figure 4) shows a higher overall efficiency than its internal processes, Khavarmianeh bank’s efficiency scores (labeled '19' in Figure 4) reveal that there could have been serious inefficiencies in the operations with its collaborating, outsourced, investment bank.

For the remainder of the cases in which overall efficiency scores are between the efficiency scores of the internal processes, this could be an indicator of the operations of external 
investment banks being aligned with the internal operations of the banks. It is worth mentioning that if a conventional network DEA model was adopted for this case, the results would have overlooked the impact of an external entity, in this case an investment bank, on the operations of the bank as an outsourcer.

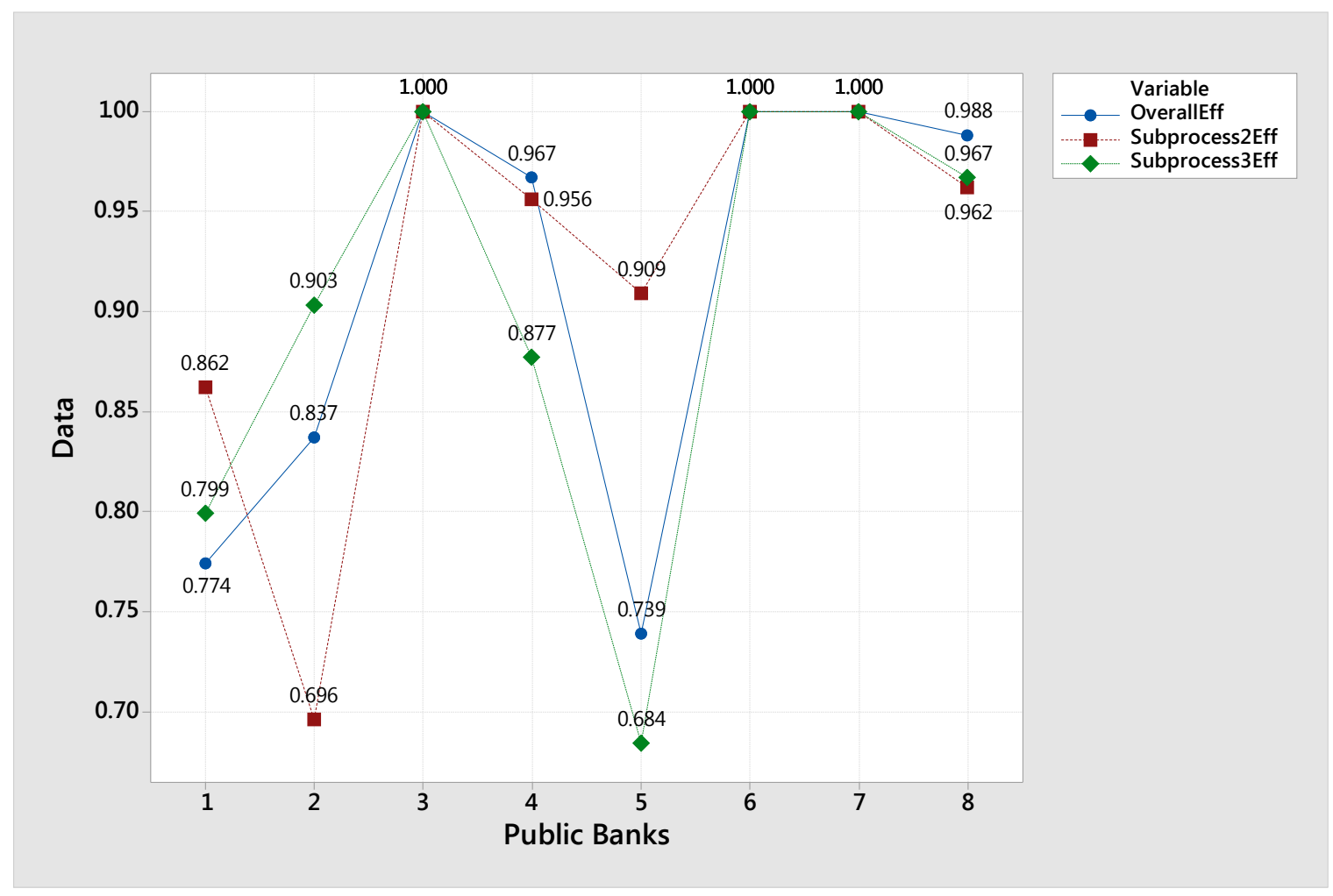

Fig. 3. Comparison of efficiency scores for public banks 


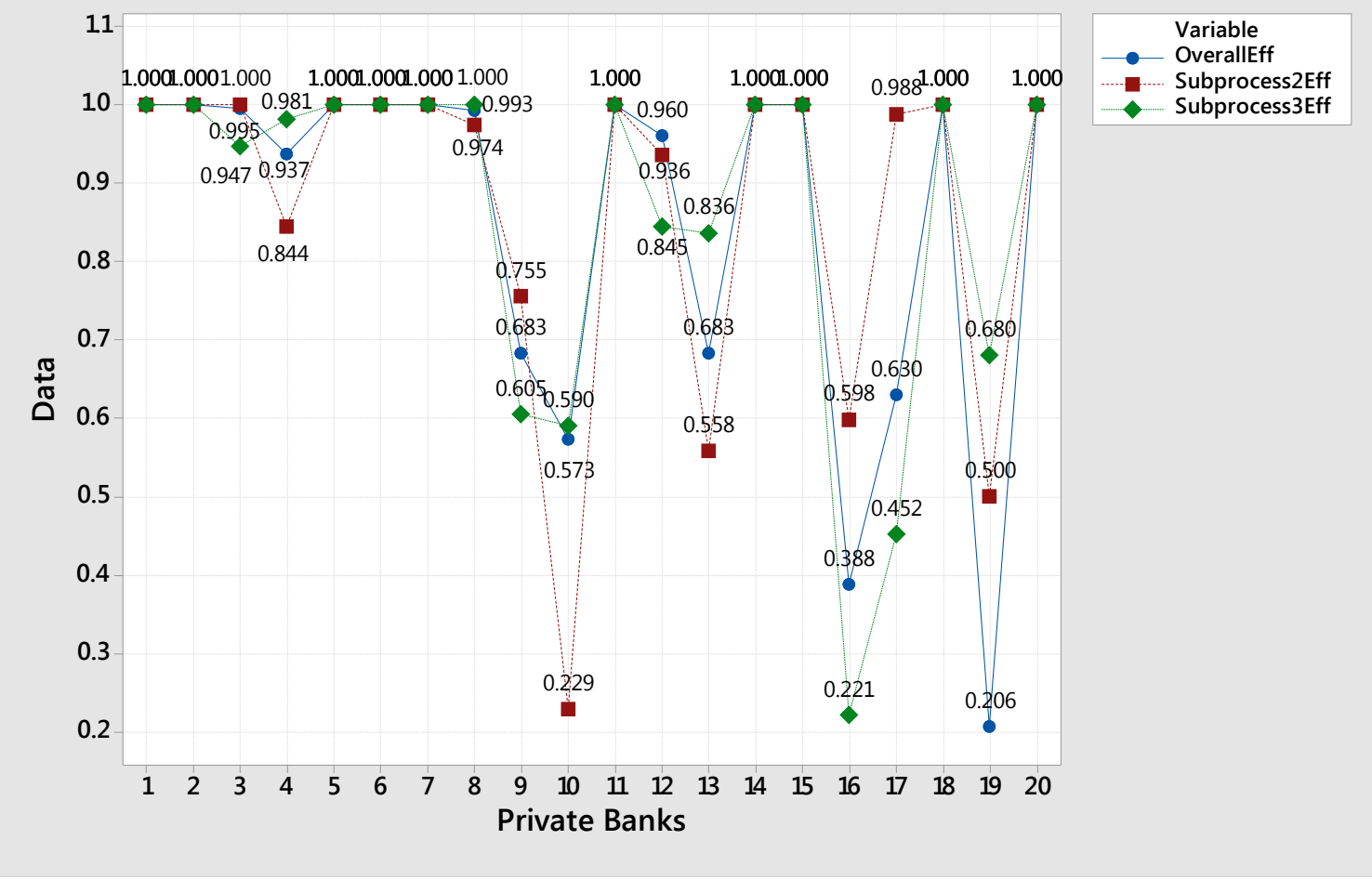

Fig. 4. Comparison of efficiency scores for private banks

\subsection{Robustness check and sensitivity analysis}

In this study, the commercial bank service supply chain included 16 exogenous and endogenous inputs and outputs for its external and internal processes. As a rule of thumb, this requires at least $16 * 3=48$ DMUs to ensure that the model will show sufficient discrimination power (Sarkis, 2007). It has been recommended that the total number of DMUs in network DEA models are multiplied by the number of sub-processes that are being investigated (Kao, 2009). Thus, having 28 DMUs and three processes $(28 * 3=84)$ satisfies the criterion for the number of DMUs required to conduct the analysis. Similar to traditional DEA, greater sample size will result into greater discrimination (Avkiran \& McCrystal, 2012).

The robustness of the proposed model is tested by switching from a variable returns-toscale to a constant returns-to-scale, and then excluding the investment bank from the original model. Constant returns-to-scale offers more discrimination power than variable returns-toscale because fewer DMUs appear on the efficient frontier. After this robustness check, the 
final range of the efficiency scores for the overall supply chain and for the internal processes remained almost the same.

Second, excluding the investment bank data from the model in Figure 2 showed a marginal increase in the efficiency scores of the overall supply chain and for the internal sub-processes. This result further confirms that excluding external influential factors in measuring the efficiency of the outsourcer (i.e. the investment bank) could overestimate its performance and lead to computational biases.

\subsection{Model Evaluation}

The network DEA model used in this study shows how performance could be evaluated in outsourcing supply chains, where there is insufficient information about the supplier operations whilst their performance do affect outsourcers operations. The novel combination of an SBM approach and network DEA model, first introduced in this study, integrates relevant information of external entities to use in the final performance evaluation of the outsourcer's processes. The proposed combined model offers greater discrimination power amongst DMUs when compared to conventional network DEA models. The new model is capable of assessing several sub-processes in addition to overall supply chain efficiency. More accurate estimations of supply chain inefficiency sources could aid supply chain managers and decision makers to more effectively address those inefficiencies, enhancing quality of their goods and services. This issue becomes especially important in service supply chains in which there is greater direct interaction with customers. Poor quality of services in these supply chains could have a greater risk of outsourcer losing customers and incurring financial losses. Although, the measures used in the case example of this study were based on financial information and data for performance evaluation, the proposed analytical model could be generally applied in different manufacturing and service contexts, using broader variety of quality and business performance metrics. 


\section{Conclusions}

Despite outsourcing strategies being widely adopted by firms around the globe, studies on organizational performance in supply chains resulting from and guiding outsourcing decisions are relatively scarce. This scarcity is even more evident in the context of service supply chains. Outsourcing management in service supply chains offers much room for improvement when compared to the more traditional manufacturing supply chains.

Given the calls for more investigations on quality issues in outsourcing, this study presented an analytical model using a combined SBM and network DEA model. The approach enables outsourcers to identify inefficiency sources using data on both internal and external entity processes. To help with validation and analysis, the model was applied to the commercial banking context in Iran. The analysis shows how performance of several public and private commercial banks and their service supply chain can be evaluated. Statistical inference testing of the results showed differences in performance of public and private banks interest-bearing operations. The results also showed how outsourcing to external entities could influence the overall efficiency of a supply chain, either positively or negatively.

This article contributes to the outsourcing and supply chain management literature by evaluating a significant set of processes in internal and external entities. The processes can be evaluated using multiple factors that could affect quality and performance in supply chains that outsource their operations to external entities. The hybrid network DEA model introduced in this study incorporates exogenous and endogenous inputs and outputs used to prepare the final product or service offered by an outsourcer. By combining the hybrid network DEA model with a general SBM approach, limitations of traditional network DEA models in terms of prespecification of weights for processes and relatively low discrimination power of these models 
were eliminated. SBM also enables the network DEA models to account for weakly efficient DMUs, hence increasing the accuracy of the results.

The analytical model presented in this study is applicable to a larger context of manufacturing and services supply chains with flexibility for performance measurement metrics selected. The model is mostly suitable when there is information asymmetry between different tiers in supply chains and when the outsourcer's knowledge and understanding of the processes related to external upstream or downstream supply chain members are limited.

This study has limitations. The inputs and outputs of the presented model involve merely quantifiable and financial criteria that are more accessible and easy to measure. However, for qualitative assessment criteria (e.g., Srinivasan \& Kurey, 2014) to be incorporated in the model, more sophisticated approaches such as fuzzy network DEA (Kao, 2014b) could be leveraged to address the uncertainties associated with the aforementioned criteria. We suggest the application of $\alpha$-cut approach (Kao \& Liu, 2011). First, triangular fuzzy numbers of inputs, outputs and the intermediate products need to be developed. Next, upper bound and lower bound of the $\alpha$-cut of $E_{o}$ (2a-2h) need to be calculated for different values of $\alpha$ varying between 0 and 1. At $\alpha=0$ the range of all possible efficiency scores for different values of $\alpha$ is determined. Moreover, at $\alpha=1$, the most likely efficiency score for the DMUs is obtained. Despite additional discrimination power of the DEA model when combined with the SBM measure, the number of DMUs needs to be significantly larger than basic DEA models (see Sub-section 5.1) to ensure that the results have sufficient discrimination power.

Future research can focus on incorporating into the model both behavioral and operational factors that could affect quality of outsourced supply chains. In general, including behavioral factors in analytical models of operations and supply chain management results in better predictability and compliance of these models to operating systems (Giannoccaro \& Ilaria, 
2013). Moreover, the latter could specifically enhance the precision of analytical models (e.g., supply chain performance measurement models) that are used to make managerial decisions (Tiwana et al., 2007; Hämäläinen et al., 2013). For instance the level of trust (Brinkhoff et al., 2015a; Brinkhoff et al., 2015b) between the outsourcer and supplier is a proven detrimental factor affecting final products and services characteristics delivered by the supply chain. In fact, a variety of behavioral criteria in intra-organizational and inter-organizational relations (Gino \& Pisano, 2008; E. Bendoly et al., 2010) could be prioritized and included in the proposed model, which in turn could offer a better understanding of quality issues in outsourcing supply chains.

It is nevertheless worth mentioning that such approaches are generally considered to be making the mathematical models even more complex and sometimes difficult to solve (Mingers, 2011). This assumption however has been revisited by Elliot Bendoly et al. (2006, p. 739, p. 739) who argue that "the two methodologies [i.e., mathematical models of operations and methods used for studying human behavior] can complement each other with each positing useful directions of inquiry for the other”. In fact, Elliot Bendoly et al. (2015) suggests that such mixed models introduce new opportunities to better comprehend and manage operations within a given context. The application of multi-methods is hence strongly recommended to first obtain the behavioral data using laboratory and field experiments and then aggregate the behavioral data with quantitative data for incorporation into the model (Elliot Bendoly \& Eckerd, 2013; T.M. Choi et al., 2016). More advanced models may also be required to better express the hierarchical structure of companies and the internal structures of DMUs.

The proposed model in this study was developed to assess quality of performance for outsourcing in service supply chains. The use of this model in more operational and manufacturing contexts requires to primarily revisiting the inputs, outputs, and intermediate products in the manufacturing supply chain such as production and procurement facilities, 
speed to market, safety, etc. (for a full list of relevant metrics see, Gunasekaran et al., 2015). Another issue to consider here is that a more realistic account of network structures has been argued to be triadic structures for both manufacturing and service supply networks (Niranjan \& Metri, 2008; T. Y. Choi \& Wu, 2009). A triadic structure for both manufacturing and service contexts has its unique characteristics in terms of the interconnections between the triad members, which should be taken into account while developing the performance assessment models such as different variations of network DEA.

Overall, this study provides some additional foundation for modeling and evaluation of outsourcing services, especially from a quality perspective. Evaluation and benchmarking with respect to cost, flexibility, time, and other measures can be easy extensions as long as data is available. Given the importance of outsourced activities and internal process implications, data that helps integrate and link the broader supply chain will need to be captured. Tools such as the one provided here can help organizations identify performance measures and relevant analytical models within the outsourcing context. Setting this foundation, ample opportunities for future research exist; not only in this context, but in more general context of performance evaluation of outsourced activities.

\section{References}

Adams, S. M., Sarkis, J., \& Liles, D. (1995). The Development of Strategic Performance Metrics. Engineering Management Journal, 7(1), 24-32. doi:

10.1080/10429247.1995.11414823

Adler, N., Friedman, L., \& Sinuany-Stern, Z. (2002). Review of ranking methods in the data envelopment analysis context. European Journal of Operational Research, 140(2), 249265. doi: http://dx.doi.org/10.1016/S0377-2217(02)00068-1

Akther, S., Fukuyama, H., \& Weber, W. L. (2013). Estimating two-stage network Slacksbased inefficiency: An application to Bangladesh banking. Omega, 41(1), 88-96. doi: http://dx.doi.org/10.1016/j.omega.2011.02.009 
Avkiran, N. K. (2015). An illustration of dynamic network DEA in commercial banking including robustness tests. Omega, 55, 141-150. doi:

http://dx.doi.org/10.1016/j.omega.2014.07.002

Avkiran, N. K., \& McCrystal, A. (2012). Sensitivity analysis of network DEA: NSBM versus NRAM. Applied Mathematics and Computation, 218(22), 11226-11239. doi: http://dx.doi.org/10.1016/j.amc.2012.05.014

Bae, S. H., Yoo, C. S., \& Sarkis, J. (2009). Outsourcing with quality competition: insights from a three-stage game-theoretic model. International journal of production research, 48(2), 327-342. doi: 10.1080/00207540903174882

Bai, C., \& Sarkis, J. (2012). Supply-chain performance-measurement system management using neighbourhood rough sets. International journal of production research, 50(9), 2484-2500. doi: 10.1080/00207543.2011.581010

Banker, R. D., Charnes, A., \& Cooper, W. W. (1984). Some Models for Estimating Technical and Scale Inefficiencies in Data Envelopment Analysis. Management Science, 30(9), 1078-1092. doi: doi:10.1287/mnsc.30.9.1078

Bardhan, A., \& Kroll, C. A. (2003). The new wave of outsourcing Fisher Center for Real Estate \& Urban Economics Research Report Series.

Bendoly, E., Croson, R., Goncalves, P., \& Schultz, K. (2010). Bodies of Knowledge for Research in Behavioral Operations. Production and Operations Management, 19(4), 434452. doi: 10.1111/j.1937-5956.2009.01108.x

Bendoly, E., Donohue, K., \& Schultz, K. L. (2006). Behavior in operations management: Assessing recent findings and revisiting old assumptions. Journal of Operations Management, 24(6), 737-752. doi: 10.1016/j.jom.2005.10.001

Bendoly, E., \& Eckerd, S. (2013). Behavioral OM Experiments: Critical Inquiry Reawakening Practical Issues in Research. In I. Giannoccaro (Ed.), Behavioral Issues in Operations Management (pp. 1-22): Springer London.

Bendoly, E., van Wezel, W., \& Bachrach, D. G. (2015). The Handbook of Behavioral Operations Management: Social and Psychological Dynamics in Production and Service Settings. New York, NY: Oxford University Press.

Brinkhoff, A., Özer, O., \& Sargut, G. (2015a). All you need is trust? An examination of interorganizational supply chain projects. Production and Operations Management, 24(2), 181-200. doi: 10.1111/poms.12234

Brinkhoff, A., Özer, Ö., \& Sargut, G. (2015b). All You Need Is Trust? An Examination of Inter-organizational Supply Chain Projects. Production and Operations Management, 24(2), 181-200. doi: 10.1111/poms.12234

Bustinza, O. F., Arias-Aranda, D., \& Gutierrez-Gutierrez, L. (2010). Outsourcing, competitive capabilities and performance: an empirical study in service firms. International Journal of Production Economics, 126(2), 276-288. doi: http://dx.doi.org/10.1016/j.ijpe.2010.03.023

Caniato, F., Elia, S., Luzzini, D., Piscitello, L., \& Ronchi, S. (2015). Location drivers, governance model and performance in service offshoring. International Journal of Production Economics, 163, 189-199. doi: http://dx.doi.org/10.1016/j.ijpe.2014.09.011

Chang, T.-S., Tone, K., \& Wei, Q. (2014). Ownership-specified network DEA models. Annals of Operations Research, 214(1), 73-98. doi: DOI 10.1007/s10479-011-0949-5

Charnes, A., Cooper, W. W., \& Rhodes, E. (1978). Measuring the efficiency of decision making units. European Journal of Operational Research, 2(6), 429-444. doi: http://dx.doi.org/10.1016/0377-2217(78)90138-8

Chen, C., \& Yan, H. (2011). Network DEA model for supply chain performance evaluation. European Journal of Operational Research, 213(1), 147-155. doi: DOI 10.1016/j.ejor.2011.03.010 
Chen, J., Liang, L., \& Yang, F. (2015). Cooperative quality investment in outsourcing. International Journal of Production Economics, 162, 174-191. doi: http://dx.doi.org/10.1016/j.ijpe.2015.01.019

Choi, T.-M., Cheng, T. C. E., \& Zhao, X. (2016). Multi-Methodological Research in Operations Management. Production and Operations Management, 25(3), 379-389. doi: 10.1111/poms.12534

Choi, T. Y., \& Wu, Z. (2009). Taking the leap from dyads to triads: Buyer-supplier relationships in supply networks. Journal of Purchasing and Supply Management, 15(4), 263-266. doi: http://dx.doi.org/10.1016/j.pursup.2009.08.003

Cook, W. D., \& Seiford, L. M. (2009). Data envelopment analysis (DEA) - Thirty years on. European Journal of Operational Research, 192(1), 1-17. doi: 10.1016/j.ejor.2008.01.032

Cooper, W. W., Seiford, L. M., \& Tone, K. (2006). Introduction to data envelopment analysis and its uses: with DEA-solver software and references. New York: Springer.

Ellram, L. M., Tate, W. L., \& Billington, C. (2007). Services Supply Management: The Next Frontier for Improved Organizational Performance (Vol. 49).

Ellram, L. M., Tate, W. L., \& Billington, C. (2008). Offshore outsourcing of professional services: A transaction cost economics perspective. Journal of Operations Management, 26(2), 148-163. doi: http://dx.doi.org/10.1016/j.jom.2007.02.008

Fare, R. (1991). Measuring Farrell efficiency for a firm with intermediate inputs. Academia Economic Papers, 19(2), 329-340.

Fare, R., \& Grosskopf, S. (2000). Network DEA. Socio-Economic Planning Sciences, 34(1), 35-49. doi: http://dx.doi.org/10.1016/S0038-0121(99)00012-9

Fare, R., Grosskopf, S., \& Brännlund, R. (1996). Intertemporal production frontiers: with dynamic DEA. Boston: Kluwer Academic Boston.

Farrell, D., Laboissière, M. A., \& Rosenfeld, J. (2006). Sizing the Emerging Global Labor Market:: Rational Behavior from Both Companies and Countries Can Help It Work More Efficiently. The Academy of Management Perspectives, 20(4), 23-34. doi: 10.5465/amp.2006.23270304

Feng, B., Fan, Z.-P., \& Li, Y. (2011). A decision method for supplier selection in multiservice outsourcing. International Journal of Production Economics, 132(2), 240-250. doi: http://dx.doi.org/10.1016/j.ijpe.2011.04.014

Fethi, M. D., \& Pasiouras, F. (2010). Assessing bank efficiency and performance with operational research and artificial intelligence techniques: A survey. European Journal of Operational Research, 204(2), 189-198. doi: http://dx.doi.org/10.1016/j.ejor.2009.08.003

Franca, R. B., Jones, E. C., Richards, C. N., \& Carlson, J. P. (2010). Multi-objective stochastic supply chain modeling to evaluate tradeoffs between profit and quality. International Journal of Production Economics, 127(2), 292-299. doi: 10.1016/j.ijpe.2009.09.005

Fukuyama, H., \& Mirdehghan, S. M. (2012). Identifying the efficiency status in network DEA. European Journal of Operational Research, 220(1), 85-92. doi: DOI 10.1016/j.ejor.2012.01.024

Giannoccaro, I., \& Ilaria, G. (2013). Behavioral Issues in Operations Management New Trends in Design, Management, and Methodologies / Giannoccaro, Ilaria. S.l.]: S.l. : Springer London.

Gino, F., \& Pisano, G. (2008). Toward a Theory of Behavioral Operations. M\&SomManufacturing \& Service Operations Management, 10(4), 676-691. doi: 10.1287/msom.1070.0205

Gray, J. V., Tomlin, B., \& Roth, A. V. (2009). Outsourcing to a Powerful Contract Manufacturer: The Effect of Learning-by-Doing. Production and Operations Management, 18(5), 487-505. doi: 10.1111/j.1937-5956.2009.01024.x 
Gunasekaran, A., Irani, Z., Choy, K.-L., Filippi, L., \& Papadopoulos, T. (2015). Performance measures and metrics in outsourcing decisions: A review for research and applications. International Journal of Production Economics, 161, 153-166. doi: http://dx.doi.org/10.1016/j.ijpe.2014.12.021

Hallikas, J. M., Karvonen, I., Pulkkinen, U., Virolainen, V.-M., \& Tuominen, M. (2004). Risk management processes in supplier networks. International Journal of Production Economics, 90(1), 47-58. doi: http://dx.doi.org/10.1016/j.ijpe.2004.02.007

Hämäläinen, R. P., Luoma, J., \& Saarinen, E. (2013). On the importance of behavioral operational research: The case of understanding and communicating about dynamic systems. European Journal of Operational Research, 228(3), 623-634. doi: http://dx.doi.org/10.1016/j.ejor.2013.02.001

Handley, S. M., \& Benton Jr, W. C. (2013). The influence of task- and location-specific complexity on the control and coordination costs in global outsourcing relationships. Journal of Operations Management, 31(3), 109-128. doi: http://dx.doi.org/10.1016/j.jom.2012.12.003

Handley, S. M., \& Gray, J. V. (2013). Inter-organizational quality management: The use of contractual incentives and monitoring mechanisms with outsourced manufacturing. Production and Operations Management, 22(6), 1540-1556. doi: 10.1111/j.19375956.2012.01351.x

Holcomb, T. R., \& Hitt, M. A. (2007). Toward a model of strategic outsourcing. Journal of Operations Management, 25(2), 464-481. doi: http://dx.doi.org/10.1016/j.jom.2006.05.003

Kao, C. (2014a). Efficiency decomposition in network data envelopment analysis with slacks-based measures. Omega, 45, 1-6. doi: 10.1016/j.omega.2013.12.002

Kao, C. (2014b). Network Data Envelopment Analysis with Fuzzy Data. In A. Emrouznejad \& M. Tavana (Eds.), Performance Measurement with Fuzzy Data Envelopment Analysis (Vol. 309, pp. 191-206): Springer Berlin Heidelberg.

Kao, C., \& Hwang, S.-N. (2008). Efficiency decomposition in two-stage data envelopment analysis: An application to non-life insurance companies in Taiwan. European Journal of Operational Research, 185(1), 418-429. doi: http://dx.doi.org/10.1016/j.ejor.2006.11.041

Kao, C., \& Liu, S.-T. (2011). Efficiencies of two-stage systems with fuzzy data. Fuzzy Sets and Systems, 176(1), 20-35. doi: http://dx.doi.org/10.1016/j.fss.2011.03.003

Kaya, M., \& Özer, Ö. (2009). Quality risk in outsourcing: Noncontractible product quality and private quality cost information. Naval Research Logistics (NRL), 56(7), 669-685. doi: 10.1002/nav.20372

Kenneth H Wathne, \& Heide, J. B. (2000). Opportunism in Interfirm Relationships: Forms, Outcomes, and Solutions. Journal of Marketing, 64(4), 36-51. doi: doi:10.1509/jmkg.64.4.36.18070

Kenyon, G. N., Meixell, M. J., \& Westfall, P. H. (2016). Production outsourcing and operational performance: An empirical study using secondary data. International Journal of Production Economics, 171, Part 3, 336-349. doi: http://dx.doi.org/10.1016/j.ijpe.2015.09.017

Kouvelis, P., Chambers, C., \& Wang, H. (2006). Supply Chain Management Research and Production and Operations Management: Review, Trends, and Opportunities. Production and Operations Management, 15(3), 449-469. doi: 10.1111/j.1937-5956.2006.tb00257.x

Lee, H. L. (1997). The bullwhip effect in supply hains. MIT Sloan Management Review, 38(3), 93-102.

Lewin, A., \& Peeters, C. (2006). The top-line allure of off-shoring. Harvard Business Review, 84, 22-24. 
Liang, L., Yang, F., Cook, W., \& Zhu, J. (2006). DEA models for supply chain efficiency evaluation. Annals of Operations Research, 145(1), 35-49. doi: 10.1007/s10479-0060026-7

Liu, J. S., Lu, L. Y. Y., Lu, W.-M., \& Lin, B. J. Y. (2013a). Data envelopment analysis 19782010: A citation-based literature survey. Omega, 41(1), 3-15. doi: 10.1016/j.omega.2010.12.006

Liu, J. S., Lu, L. Y. Y., Lu, W.-M., \& Lin, B. J. Y. (2013b). A survey of DEA applications. Omega, 41(5), 893-902. doi: 10.1016/j.omega.2012.11.004

Matthews, K. (2013). Risk management and managerial efficiency in Chinese banks: A network DEA framework. Omega, 41(2), 207-215. doi: DOI 10.1016/j.omega.2012.06.003

McIvor, R. (2009). How the transaction cost and resource-based theories of the firm inform outsourcing evaluation. Journal of Operations Management, 27(1), 45-63. doi: http://dx.doi.org/10.1016/j.jom.2008.03.004

Mingers, J. (2011). Soft OR comes of age—but not everywhere! Omega, 39(6), 729-741. doi: http://dx.doi.org/10.1016/j.omega.2011.01.005

Mirhedayatian, S. M., Azadi, M., \& Farzipoor Saen, R. (2014). A novel network data envelopment analysis model for evaluating green supply chain management. International Journal of Production Economics, 147, 544-554. doi: 10.1016/j.ijpe.2013.02.009

Niranjan, T., \& Metri, B. A. (2008). Client-Vendor-End User Triad: A Service Quality Model for Is/Ites Outsourcing. Journal of Services Research, 8(1), 123-138.

Perdikaki, O., Peng, D. X., \& Heim, G. R. (2015). Impact of Customer Traffic and Service Process Outsourcing Levels on e-Retailer Operational Performance. Production and Operations Management, n/a-n/a. doi: 10.1111/poms.12359

Robinson, C. J., \& Malhotra, M. K. (2005). Defining the concept of supply chain quality management and its relevance to academic and industrial practice. International Journal of Production Economics, 96(3), 315-337. doi: http://dx.doi.org/10.1016/j.ijpe.2004.06.055

Roth, A. V., \& Menor, L. J. (2003). Insights into service operations management: A research agenda. Production and Operations Management, 12(2), 145-164. doi: 10.1111/j.19375956.2003.tb00498.x

Sanders, N. R., Locke, A., Moore, C. B., \& Autry, C. W. (2007). A Multidimensional Framework for Understanding Outsourcing Arrangements. Journal of Supply Chain Management, 43(4), 3-15. doi: 10.1111/j.1745-493X.2007.00037.x

Sarkis, J. (2007). Preparing Your Data for DEA. In J. Zhu \& W. Cook (Eds.), Modeling Data Irregularities and Structural Complexities in Data Envelopment Analysis (pp. 305-320): Springer US.

Sarkis, J., \& Talluri, S. (1996). Efficiency valuation and internal benchmarking for business process improvement. Journal of Engineering Valuation and Cost Analysis, 1(1), 43-54.

Sousa, R., \& Voss, C. A. (2002). Quality management re-visited: a reflective review and agenda for future research. Journal of Operations Management, 20(1), 91-109. doi: http://dx.doi.org/10.1016/S0272-6963(01)00088-2

Srinivasan, A., \& Kurey, B. (2014). Creating a culture of quality. Harvard Business Review, 92(4), 23-25.

Steven, A. B., Dong, Y., \& Corsi, T. (2014). Global sourcing and quality recalls: An empirical study of outsourcing-supplier concentration-product recalls linkages. Journal of Operations Management, 32(5), 241-253. doi:

http://dx.doi.org/10.1016/j.jom.2014.04.003 
Tate, W. L., Ellram, L. M., Bals, L., \& Hartmann, E. (2009). Offshore outsourcing of services: An evolutionary perspective. International Journal of Production Economics, 120(2), 512-524. doi: http://dx.doi.org/10.1016/j.ijpe.2009.04.005

Thanassoulis, E., Portela, M. C., \& Despic, O. (2008). Data envelopment analysis: The mathematical programming approach to efficiency analysis. In H. Fried, C. A. KnoxLovell \& S. Schmidt (Eds.), The measurement of productive efficiency and productivity growth (pp. 251-420). Oxford: Oxford University Press.

Tiwana, A., Wang, J., Keil, M., \& Ahluwalia, P. (2007). The Bounded Rationality Bias in Managerial Valuation of Real Options: Theory and Evidence from IT Projects. Decision Sciences, 38(1), 157-181. doi: 10.1111/j.1540-5915.2007.00152.x

Tone, K., \& Tsutsui, M. (2009). Network DEA: A slacks-based measure approach. European Journal of Operational Research, 197(1), 243-252. doi: DOI 10.1016/j.ejor.2008.05.027

Tse, Y. K., \& Tan, K. H. (2012). Managing product quality risk and visibility in multi-layer supply chain. International Journal of Production Economics, 139(1), 49-57. doi: 10.1016/j.ijpe.2011.10.031

Wagner, S. M., \& Bode, C. (2008). An empirical examination of supply chain performance along several dimensions of risk. Journal of Business Logistics, 29(1), 307-325. doi: 10.1002/j.2158-1592.2008.tb00081.x

Wuyts, S., Rindfleisch, A., \& Citrin, A. (2015). Outsourcing customer support: The role of provider customer focus. Journal of Operations Management, 35(0), 40-55. doi: http://dx.doi.org/10.1016/j.jom.2014.10.004

Xiao, T., Xia, Y., \& Zhang, G. P. (2014). Strategic outsourcing decisions for manufacturers competing on product quality. Iie Transactions, 46(4), 313-329. doi: 10.1080/0740817X.2012.761368

Xu, J., Li, B., \& Wu, D. (2009). Rough data envelopment analysis and its application to supply chain performance evaluation. International Journal of Production Economics, 122(2), 628-638. doi: http://dx.doi.org/10.1016/j.ijpe.2009.06.026

Yang, Z., Aydin, G., Babich, V., \& Beil, D. R. (2009). Supply disruptions, asymmetric information, and a backup production option. Management Science, 55(2), 192-209.

You, Y. Q., \& Jie, T. (In press). A study of the operation efficiency and cost performance indices of power-supply companies in China based on a dynamic network slacks-based measure model. Omega. doi: http://dx.doi.org/10.1016/j.omega.2014.11.011 